$1-1-2021$

Relationship of BMI with Junk Food, sleep pattern, exam performance and awareness about its ill health effects in healthy teenagers

Saba Tariq

Sundus Tariq

Saffee Tariq

Rehana Rehman

Follow this and additional works at: https://ecommons.aku.edu/pakistan_fhs_mc_bbs

Part of the Life Sciences Commons 


\title{
Relationship of BMI with Junk Food, sleep pattern, exam performance and awareness about its ill health effects in healthy teenagers
}

Saba Tariq ${ }^{1}$, Sundus Tariq ${ }^{2}$, Saffee Tariq ${ }^{3}$, Rehana Rehman ${ }^{4}$

\begin{abstract}
Objective: To evaluate the relationship of body mass index of healthy teenagers with junk food, sleep pattern, exam performance and awareness about its ill effects.

Methods: The cross-sectional study was conducted from March to June 2017 at University Medical and Dental College, University of Faisalabad, Faisalabad, Pakistan, and comprised subjects aged 13-19. Data was collected using face-to-face interviews, getting the examnation results from respective educational insititutions and calculating the body mass index, Data was analysed using SPSS 22.

Results: Of the 226 subjects, $96(42.5 \%)$ were boys with a mean age of $15.68 \pm 1.83$ years, and $130(57.5 \%)$ were girls with a mean age of $17.00 \pm 1.74$ years. Based on body mass index, $35(15.5 \%)$ subjects were underweight, $88(39 \%)$ were normal, $28(12.4 \%)$ overweight, $56(24.7 \%)$ pre-obese and $19(8.4 \%)$ were obese. The independent predictors of body mass index were higher consumption of soft drinks in males and higher consumption of soft drinks and salt in females $(p<0.05)$.

Conclusion: Teenagers were found to be well aware of the ill effects of junk food, but they were found to be happy with their dietary habits and unwilling to change it.

Keywords: Teenagers, BMI, Food habits, Fast food, Soft drinks. (JPMA 71: 59; 2021) DOI: https://doi.org/10.47391/JPMA.507
\end{abstract}

\section{Introduction}

Healthy diet is essential in combating non-communicable diseases, like diabetes mellitus (DM) and obesity. ${ }^{1}$ Junk food, also known as fast food, has become increasingly popular in Pakistan. Many factors have led to an increase in junk food consumption; one of the important factors is its easy availability to students in school and college cafeterias. It has also been seen that the junk food restaurants have grown rapidly across Pakistan which provide door-to-door delivery of junk food. ${ }^{2}$ The increasing trend of consuming junk food has been witnessed all over the world due to easy availability and accessibility of a variety of delicious fast food items at very affordable prices. ${ }^{3}$ However, the fact should not be ignored that junk food has a high caloric value which results in serious health problems when consumed excessively, leading to obesity, dental cavities and DM which are few of the diseases whose prevalence is increasing and it can affect the exam performance as well of the students. 4

A disturbed sleep pattern has been associated with obesity as it results in increased appetite and craving for salty, sweet and fried food, which, when consumed excessively,

1Department of Pharmacology, University Medical and Dental College, Faisalabad, Pakistan; 2Department of Physiology, University Medical and Dental College, Faisalabad, Pakistan; ${ }^{3}$ Rawal pindi Medical University, Rawalpindi, Pakistan; ${ }^{4}$ Department of Physiology, Aga Khan University Hospital, Karachi, Pakistan

Correspondence: Saba Tariq. e-mail: drsabatariq1@gmail.com has a detrimental effect on the health of teenagers. 5 Studies have shown that a decreased intake of fruits and vegetables along with an increased intake of fast food results in sleep disturbance which has an overall impact on daily routine of the individuals. 6

A healthy diet exalts exam performance unlike junk food which can lead to poor exam performance.7,8 The current study was planned to see the relationship of body mass index (BMI) with junk food, sleep pattern, exam performance and awareness about its ill effects on health.

\section{Subjects and Methods}

The cross-sectional study was conducted from March to June 2017 at University Medical and Dental College, University of Faisalabad, Faisalabad, Pakistan, and comprised teenaged students. After approval from the institutional ethics review committee, the sample size was calculated using the formula $n=N X /(X+N-1)$, where $X=$ $(Z a / 2) \wedge 2[p(1-p)] / e^{\wedge} 2$. In the formula, $n=$ sample size, $\mathrm{Za} / 2=$ critical value of normal distribution at $\mathrm{a} / 2$, $\alpha$ is 0.05 and critical value is 1.96 , while $p$ is the sample proportion and $\mathrm{N}$ is the population size). The prevalence of junk food consumption was taken as $11 \%, 9$ errors (e) of $5 \%$ and confidence interval $(\mathrm{Cl})$ of $95 \%$.

The sample was raised using multistage sampling technique. A list of all private schools in Faisalabad providing secondary education to the students was collected. From the list five schools were selected randomly, and from these five, schools lists of all students 
enrolled were obtained from their respective managements. Those included were healthy subjects aged 13-19 who were willing to volunteer for the study. Students with any known disease, such as inflammatory bowel disease, cystic fibrosis, coeliac disease, and known food allergy or food intolerance, were excluded, and so were those having any psychiatric eating disorder.

After taking written informed consent from the participants or their guardians, data was collected through face-to-face interviews regarding demographics, dietary and sleeping habits using a specially designed proforma. ${ }^{10}$ Test scores of the students were obtained from the respective educational insititutions. BMI was calculated after taking height and weight measurements using standardised equipment and standard procedure. The subjects were divided into various BMI groups using the the Asian classification of the World Health Organization (WHO), ${ }^{11}$ labelled as: underweight <18.5, normal 18.5-22.9, overweight 23-24.9, pre-obese 25-29.9, and obese $>30$.

Data was analysed using SPSS 22. For qualitative variables, data was presented as frequencies and percentages. For quantitative variables, it was presented as mean \pm standard deviation (SD). Independent sample t test and chi-square tests was used for inter-group comparisons. Analysis of variance (ANOVA) followed by post-hoc analysis was done for multiple comparisons among BMI groups. Pearson's correlation was applied to observe correlation between quantitative variables. Multivariate linear stepwise regression analysis was used to see the predictors of BMI. $\mathrm{P} \leq 0.05$ was considered statistically significant.

\section{Results}

Of the 226 subjects, 96(42.5\%) were boys with a mean age of $15.68 \pm 1.83$ years and mean BMI 22.79 \pm 4.31 , and $130(57.5 \%)$ were girls with a mean age of $17.00 \pm 1.74$ years and mean BMI 22.43 \pm 5.39 . Exam performance of girls was significantly higher compared to boys $(p<0.05)$. The reasons given by students for their consumption of junk food and their perception of factors causing obesity or health problems were noted (Table 1).

Based on BMI, 35(15.5\%) subjects were underweight, $88(39 \%)$ normal, 28(12.4\%) overweight, $56(24.7 \%)$ preobese and 19(8.4\%) were obese. Healthy and unhealthy food consumption in various BMl groups were noted and there were significant
Table-1: Comparison of study variables between the groups.

\begin{tabular}{|c|c|c|c|}
\hline Anthropometric measures & $\begin{array}{c}\text { Male }(n=96) \\
\text { Mean } \pm \text { SD }\end{array}$ & $\begin{array}{c}\text { Female }(n=130) \\
\text { Mean } \pm \text { SD }\end{array}$ & $p$-value \\
\hline Age (years) & $15.68 \pm 1.83$ & $17.00 \pm 1.74$ & $<0.05^{*}$ \\
\hline Height (meters) & $1.55 \pm 0.17$ & $1.52 \pm 0.13$ & 0.101 \\
\hline Weight (kgs) & $54.73 \pm 12.72$ & $53.04 \pm 9.64$ & 0.258 \\
\hline Body mass index (BMI) & $22.79 \pm 4.31$ & $22.43 \pm 5.39$ & 0.34 \\
\hline Average sleep hours & $7.88 \pm 1.65$ & $7.70 \pm 1.75$ & 0.448 \\
\hline Average scores & $73.99 \pm 13.34$ & $82.12 \pm 10.52$ & $<0.05^{*}$ \\
\hline \multicolumn{4}{|c|}{ Reasons for the consumption of junk food among teenagers } \\
\hline & Males $\mathbf{n}(\%)$ & Females n (\%) & $p$-value \\
\hline You like it & $60(62.5)$ & $95(73.1)$ & 0.061 \\
\hline It's easy to find, it's everywhere & $29(30.2)$ & $23(17.7)$ & $<0.05^{*}$ \\
\hline It's convenient and fast & $16(16.7)$ & $22(16.9)$ & 0.554 \\
\hline It doesn't cost much & $16(16.7)$ & $7(5.4)$ & $<0.05^{*}$ \\
\hline The servings are larger & $9(9.4)$ & $9(6.9)$ & 0.333 \\
\hline You want to be like others & $16(16.7)$ & $1(0.8)$ & $<0.05^{*}$ \\
\hline \multicolumn{4}{|c|}{ Teenagers perception of factors causing obesity or health problems } \\
\hline & Males $\mathbf{n}(\%)$ & Females n (\%) & $p$-value \\
\hline $\begin{array}{l}\text { Frequent consumption of soft drinks } \\
\text { and sweetened drinks }\end{array}$ & $16(16.7)$ & $42(32.3)$ & $<0.05^{*}$ \\
\hline Frequent consumption of fast food meals & Is $17(17.7)$ & $54(41.5)$ & $<0.05^{*}$ \\
\hline Lack of physical activity & $38(39.6)$ & $49(37.7)$ & 0.440 \\
\hline The influence of marketing of junk food & $13(13.5)$ & $9(6.9)$ & 0.104 \\
\hline \multicolumn{4}{|c|}{ (e.g., advertising, packaging, low prices, etc.) } \\
\hline You don't know & $6(6.3)$ & $4(3.1)$ & 0.206 \\
\hline
\end{tabular}

differences (Table 2).

The relation of BMI with unhealthy and healthy food consumption, average sleep hours and test scores in college students were explored (Table 3 ).

Stepwise multiple regression analysis model accounted

Table-2: Comparison of healthy and unhealthy food consumption between various body mass index (BMI) groups using analysis of variance (ANOVA).

\begin{tabular}{lcccccc}
\hline Food items\# & \multicolumn{7}{c}{.BMI groups } \\
\cline { 2 - 7 } & $\begin{array}{c}\text { Underweight } \\
\mathbf{n}=\mathbf{3 5}\end{array}$ & $\begin{array}{c}\text { Normal } \\
\mathbf{n}=\mathbf{8 8}\end{array}$ & $\begin{array}{c}\text { Overweight } \\
\mathbf{n}=\mathbf{2 8}\end{array}$ & $\begin{array}{c}\text { Pre-obese } \\
\mathbf{n}=\mathbf{5 6}\end{array}$ & $\begin{array}{c}\text { Obese } \\
\mathbf{n}=\mathbf{1 9}\end{array}$ & $\boldsymbol{p}$-value \\
\hline Sweet snacks & $5.00 \pm 3.21$ & $4.33 \pm 3.34$ & $3.50 \pm 3.59$ & $4.95 \pm 3.65$ & $5.89 \pm 4.28$ & 0.150 \\
Salty snacks & $3.51 \pm 2.46$ & $3.82 \pm 2.80$ & $4.57 \pm 2.66$ & $4.52 \pm 3.28$ & $6.84 \pm 6.35$ & $<0.05^{*}$ \\
Fruit flavoured drinks & $2.69 \pm 2.46$ & $2.83 \pm 3.27$ & $2.89 \pm 3.07$ & $3.02 \pm 2.82$ & $3.21 \pm 3.06$ & 0.972 \\
Fried foods & $2.89 \pm 2.21$ & $4.20 \pm 2.69$ & $4.07 \pm 2.85$ & $4.93 \pm 2.44$ & $5.84 \pm 2.77$ & $<0.05^{*}$ \\
Soft drinks & $2.97 \pm 3.03$ & $5.14 \pm 3.43$ & $4.43 \pm 3.59$ & $5.89 \pm 4.06$ & $9.68 \pm 5.46$ & $<0.05^{*}$ \\
Fast food meals & $1.26 \pm 1.13$ & $2.10 \pm 1.85$ & $2.18 \pm 2.19$ & $3.52 \pm 2.71$ & $2.26 \pm 2.86$ & $<0.05^{*}$ \\
Sports drinks & $0.06 \pm 0.23$ & $0.74 \pm 1.68$ & $0.57 \pm 1.77$ & $1.05 \pm 2.22$ & $1.53 \pm 2.36$ & $<0.05^{*}$ \\
Vitaminised sugary waters & $0.37 \pm 1.03$ & $0.59 \pm 1.33$ & $0.39 \pm 1.42$ & $0.55 \pm 1.27$ & $1.26 \pm 1.96$ & 0.187 \\
Energy drinks & $0.46 \pm 0.85$ & $0.82 \pm 1.61$ & $0.93 \pm 1.82$ & $0.79 \pm 1.86$ & $2.05 \pm 4.77$ & 0.104 \\
Water, bottled or tap & $30.11 \pm 3.32$ & $30.74 \pm 3.22$ & $31.57 \pm 3.08$ & $31.23 \pm 3.43$ & $30.16 \pm 4.35$ & 0.342 \\
Fresh fruits & $4.00 \pm 2.21$ & $3.24 \pm 2.03$ & $2.64 \pm 2.34$ & $2.59 \pm 2.73$ & $1.63 \pm 1.92$ & $<0.05^{*}$ \\
Vegetables & $3.54 \pm 2.34$ & $3.45 \pm 1.94$ & $2.64 \pm 1.87$ & $2.73 \pm 1.98$ & $1.47 \pm 1.58$ & $<0.05^{*}$ \\
Test scores & $85.37 \pm 9.57$ & $77.48 \pm 14.42$ & $82.21 \pm 7.53$ & $76.20 \pm 10.40$ & $73.89 \pm 13.63$ & $<0.05^{*}$ \\
Average sleep hours & $7.91 \pm 1.80$ & $7.50 \pm 1.64$ & $6.89 \pm 1.28$ & $8.30 \pm 1.69$ & $8.53 \pm 1.74$ & $<0.05^{*}$ \\
\hline
\end{tabular}

BMl groups $=$ Underweight $<18.5$, Normal 18.5-22.9, Overweight 23-24.9, Pre-obese 25-29.9, 0bese $>30$

\# Consumption frequency per week is assessed for all food items. 
Table-3: Relation of body mass index (BMI) with unhealthy, healthy food consumption, average sleep hours and test scores in college students.

\begin{tabular}{lcccc}
\hline Food items & \multicolumn{2}{c}{ Male ( $\mathbf{n = 9 6 )}$} & \multicolumn{2}{c}{ Female $(\mathbf{n = 1 3 0})$} \\
\cline { 2 - 5 } & $\boldsymbol{r}$ & $\boldsymbol{p}$-value & $\boldsymbol{r}$ & $\boldsymbol{p}$-value \\
\hline Sweet snacks (e.g., candies, chocolate, cupcakes, etc.) & -0.060 & 0.560 & 0.205 & $<0.05^{*}$ \\
Salty snacks (e.g., chips, pretzels, nachos, etc.) & 0.171 & 0.096 & 0.288 & $<0.05^{*}$ \\
Fruit flavoured drinks (e.g., Fruitopia) & 0.075 & 0.466 & 0.061 & 0.487 \\
Fried foods (e.g., fries, fried chicken, etc.) & 0.233 & $<0.05^{*}$ & 0.328 & $<0.05^{*}$ \\
Soft drinks & 0.303 & $<0.05^{*}$ & 0.426 & $<0.05^{*}$ \\
Fast food meals (e.g., McDonald, Pizza Hut, etc.) & 0.065 & 0.531 & 0.299 & $<0.05^{*}$ \\
Sports drinks (e.g., Gatorade, Powerade, etc.) & 0.357 & $<0.05^{*}$ & 0.133 & 0.131 \\
Vitaminised sugary waters & 0.165 & 0.109 & 0.101 & 0.254 \\
Energy drinks (e.g., Red Bull, Monster, Guru, etc.) & 0.074 & 0.473 & 0.188 & $<0.05^{*}$ \\
Water, bottled or tap & 0.075 & 0.466 & 0.072 & 0.414 \\
Fresh fruits & -0.198 & 0.054 & -0.311 & $<0.05^{*}$ \\
Vegetables & -0.181 & 0.077 & -0.306 & $<0.05^{*}$ \\
Test scores & -0.205 & $<0.05^{*}$ & -0.297 & $<0.05^{*}$ \\
Average sleep hours & 0.142 & 0.167 & 0.174 & $<0.05^{*}$ \\
\hline
\end{tabular}

intention to change it for the better (Figure).

\section{Discussion}

The study found that the main reason for eating junk food was that the young population liked it and it was easily available. Also, though female students were more aware compared to male counterparts of the ill effects of fast food, like obesity, they were happy consuming such food. Several studies have shown similar liking of teenagers towards fast food.12-14 Our study also found that consumption of salty snacks, fried food and fast food was significantly higher in the obese group. One of the reasons could be that these Table-4: Multivariate linear stepwise analysis showing independent predictors of body mass index (BMI). snacks are easily available at the school canteen

\begin{tabular}{llcccc}
\hline & Parameters & $\boldsymbol{\beta}$-coefficient & $\mathbf{R}^{2}$ change & $\mathbf{s r}^{\mathbf{2}}$ & $\boldsymbol{p}$-value \\
\hline Males & Sports drinks & 0.643 & 0.128 & 0.074 & $<0.05^{*}$ \\
$\mathrm{R}^{2}=0.166$ & Soft drinks & 0.230 & 0.038 & 0.038 & $<0.05^{*}$ \\
Females & Soft drinks & 0.275 & 0.173 & 0.026 & $<0.05^{*}$ \\
$\mathrm{R}^{2}=0.297$ & Fresh fruits & -0.612 & 0.057 & 0.064 & $<0.05^{*}$ \\
& Scores & -0.126 & 0.037 & 0.053 & $<0.05^{*}$ \\
& Salt consumption & 0.322 & 0.030 & 0.029 & $<0.05^{*}$ \\
\hline
\end{tabular}

Dependent variable is $\mathrm{BMl}$; $\mathrm{sr}^{2}$ is the squared semi-partial correlation; $p$-value $\leq 0.05$ is considered statistically significant.

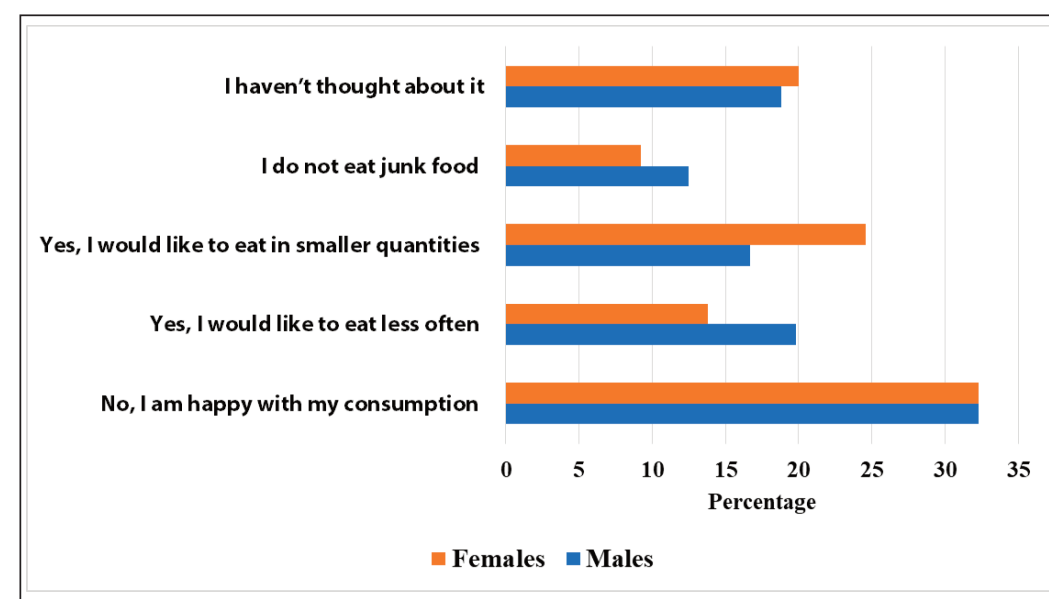

Figure: Intention to change consumption of Junk food in next few months.

showed that independent predictors of BMI in males were higher consumption of sports and soft drinks, while in females, the independent predictors were higher consumption of soft drinks and salt, and low consumption of fresh fruits and low performance in exams (Table 4).

Despite having a significant perception about the ill effects of obesity and related factors, most teenagers regardless of gender were happy with their dietary habits and had no and students are left with no other choice. A study in Brazil also found that food environment in school is one of the major causes of consumption of unhealthy food among teenagers. 15 Soft, sports and energy drinks were significantly consumed in obese groups compared to the others. Teenagers liked energy drinks because it enhanced their physical performance, cognition and concentration level during their studies. ${ }^{16} \mathrm{~A}$ study reported that these energy drinks improved myocardial contractility within one hour of consumption. ${ }^{17}$ However, the adverse effects weigh far more than the therapeutic effects of the energy drinks. It was found in a study that students who are on sports drinks have more tendencies towards eating fried and high-sugar foods than those who did not. ${ }^{18}$

Another study found that increased consumption of energy drinks is significantly associated with high BMI. ${ }^{19}$ In a study in Mexican females, researchers tried to find food associated with obesity, and it was observed that obese females were taking more soft drinks and fat compared to overweight and normal-weight females. ${ }^{20}$ Another study showed a significant association between intakes of soft drinks and type 2 DM. ${ }^{21}$ Another study saw that although students knew that sports drinks could cause dental caries and other health-related issues, they liked them because of their taste and were unable to avoid them.22 Researchers suggested that the reduction in the use of energy drinks and sports drinks is associated with a decreased risk of obesity and type 2 DM. ${ }^{23}$ 
Another finding of the current study was that there was less consumption of fruits and vegetables in the obese group compared to other groups. One study found that lower intake of fruits and vegetables were associated with obesity. ${ }^{24}$ A prospective cohort of 133,468 United States men and women showed that vegetables high in fibre and low in glycaemic content were associated with weightloss. ${ }^{25}$ Similarly, a study showed that an increased intake of fruits and vegetables in females had a $24 \%$ lower risk of becoming obese. ${ }^{26}$ Thus, it is important to motivate teenagers to include fruits and vegetables in their diet. Researchers suggested that autonomous motivation results in increased intake of fruits and vegetables both in adolescents and their parents. ${ }^{27}$ In contrast to our findings, a study found higher consumption of fruits and vegetables amongst teenagers in their diet. 28

The current study also observed that students having a higher BMI performed poorly in exams. This result is similar to a study in which obese Japanese adolescents had low grades in their exams.29 In another cross-sectional study conducted on 893 school-children showed that good fitness level was associated with higher academic performance in males compared to obese boys who showed significantly lower academic performance. This is due to the fact that higher fitness is related to improved cardio-respiratory and improved cognitive function. 30 Another study explained that obesity is one of the most important risk factors of obstructive sleep apnoea which leads to daytime sedation, fatigue, depression and overall poor academic performance. 31 Obese students are also likely to miss school more frequently, especially those with chronic health conditions, such as DM, which also leads to poor academic performance and low grades in exams. Unhealthy lifestyle is one of the major factors in gaining weight, and exercise and dietary modification is necessary among students to manage the issue.32,33

The current study found that individuals with more average sleep hours were obese. A study also found that an increase in sleep duration was significantly associated with obesity. ${ }^{32}$ However, there are studies showing an inverse relationship between sleep hours and obesity. 34,35

It was also observed in the current study that although teenagers were well aware of the ill effects of junk food, they were happy with their dietary habits and were not willing to change it. This is a matter of great concern for the policy makers, as obesity prevalence is increasing in Pakistan ${ }^{36}$ and junk food consumption is one of the major contributing factors.

\section{Conclusion}

Consumption of junk food in teenagers was found to be increasing their BMI, affecting their exam performance and sleep duration. Students were also aware about the ill health effects of junk food, but were unwilling to decrease its consumption.

Disclaimer: The Abstract has been submitted to an AMEE 2019 international conference scheduled to be held in Vienna, Austria, August 24-28, and will be published in the event's Abstract Book, if accepted.

\section{Conflict of interest: None. Source of Funding: None.}

\section{References}

1. Hilger J, Loerbroks A, Diehl K. Eating behaviour of university students in Germany: Dietary intake, barriers to healthy eating and changes in eating behaviour since the time of matriculation. Appetite. 2017; 109:100-7.

2. Cutumisu N, Traoré I, Paquette MC, Cazale L, Camirand H, Lalonde B, et al. Association between junk food consumption and fast-food outlet access near school among Quebec secondary-school children: findings from the Quebec Health Survey of High School Students (QHSHSS) 2010-11. Public Health Nutr. 2017; 20:927-37.

3. Majabadi HA, Solhi M, Montazeri A, Shojaeizadeh D, Nejat S, Farahani FK, et al. Factors influencing fast-food consumption among adolescents in tehran: a qualitative study. Iran Red Crescent Med J. 2016; 18:23890.

4. Joseph N, Nelliyanil M, Rai S, YP RB, Kotian SM, Ghosh T, et al. Fast food consumption pattern and its association with overweight among high school boys in Mangalore city of southern India. J Clin Diagn Res. 2015; 9:LC13-7.

5. Beebe DW, Simon S, Summer S, Hemmer S, Strotman D, Dolan LM. Dietary intake following experimentally restricted sleep in adolescents. Sleep. 2013; 36:827-34.

6. Stamatakis KA, Brownson RC. Sleep duration and obesity-related risk factors in the rural Midwest. Prev Med. 2008; 46:439-44.

7. Wright RS, Waldstein SR, Kuczmarski MF, Pohlig RT, Gerassimakis CS, Gaynor B, et al. Diet quality and cognitive function in an urban sample: findings from the Healthy Aging in Neighbourhoods of Diversity across the Life Span (HANDLS) study. Public Health Nutr. 2017; 20:92101.

8. Anderson ML, Gallagher J, Ritchie ER. School lunch quality and academic performance. National Bureau of Economic Research. [Online] [Cited 2017 March 03]. Available from: URL: http://www.nber.org/papers/w23218

9. Jahan N, Mehjabeen, Anjum F, Ghayas S, Yasin H, Sajid M, et al. Fast food consumption Drift in Pakistani population. J Food Nutr Sci. 2014; 2:13-8.

10. Hovington J. Junk food denormalization project for young people: junk food marketing survey: 10000 quebec teenagers speak out Montreal: Bibliothèque et Archives nationales du Québec, Bibliothèque et Archives nationales du Québec. 2012; 55.

11. Jawed S, Tariq S, Tariq S, Kamal A. Frequency of nutritional anemia among female medical students of Faisalabad. Pak J Med Sci. 2017 33:398-403.

12. ALFaris NA, Al-Tamimi JZ, Al-Jobair MO, Al-Shwaiyat NM. Trends of fast food consumption among adolescent and young adult Saudi girls living in Riyadh. Food Nut Res. 2015; 59:26488.

13. Singh MV, Singh DK, Yadav RK, Shukla KM, Sharma IK, Prajapati NC. A study of habit of fast food eating among school going adolescents and parental advice and its relation with their nutritional status. Int J Res Med Sci. 2014; 2:892-6. 
14. Akhter MM. Consumer Attitude toward Fast Food Consumption: A Study on University Students in Dhaka City. Asian J Hum Art Literature. 2019; 6:43-54.

15. Azeredo CM, de Rezende LF, Canella DS, Claro RM, Peres MF, do Carmo Luiz O, et al. Food environments in schools and in the immediate vicinity are associated with unhealthy food consumption among Brazilian adolescents. Prev Med. 2016; 88:73-9.

16. Childs E. Influence of energy drink ingredients on mood and cognitive performance. Nutr Rev. 2014; 72:48-59.

17. Doerner JM, Kuetting DL, Luetkens JA, Naehle CP, Dabir D, Homsi R, et al. Caffeine and taurine containing energy drink increases left ventricular contractility in healthy volunteers. Int J Cardiovasc Imaging. 2015; 31:595-601.

18. Williams Jr RD, Odum M, Housman JM. Adolescent energy drink use related to intake of fried and high-sugar foods. Am J Health Behav. 2017; 41:454-60.

19. Williams Jr RD, Housman JM, Odum M, Rivera AE. Energy drink use linked to high-sugar beverage intake and BMI among teens. Am J Health Behav. 2017; 41:259-65.

20. Caamaño MC, Gutierrez J, García OP, Ronquillo D, Martinez G, Rosado $\mathrm{JL}$. Increased calorie intake at a specific mid-morning meal and increased intake of soft drinks are strongly associated with obesity in Mexican rural women. Ecol Food Nutr. 2015; 54:157-74.

21. Papier K, D'este C, Bain C, Banwell C, Seubsman S, Sleigh A, et al. Consumption of sugar-sweetened beverages and type 2 diabetes incidence in Thai adults: results from an 8-year prospective study. Nutr Diabetes. 2017; 7:e283.

22. Fairchild RM, Broughton D, Morgan MZ. Knowledge of and attitudes to sports drinks of adolescents living in South Wales, UK. Br Dent J. 2017; 222:931-5.

23. Ma Y, He FJ, Yin Y, Hashem KM, MacGregor GA. Gradual reduction of sugar in soft drinks without substitution as a strategy to reduce overweight, obesity, and type 2 diabetes: a modelling study. Lancet Diabetes Endocrinol. 2016; 4:105-14.

24. Marra M, Migliardi A, Costa G. Health inequalities and nutrition in Italy during crisis times. Epidemiol Prev. 2015; 39:322-31.

25. Bertoia ML, Mukamal KJ, Cahill LE, Hou T, Ludwig DS, Mozaffarian D, et al. Changes in intake of fruits and vegetables and weight change in United States men and women followed for up to 24 years: analysis from three prospective cohort studies. PLoS Med. 2016; 13:e1001956.
26. He K, Hu FB, Colditz GA, Manson JE, Willett WC, Liu S. Changes in intake of fruits and vegetables in relation to risk of obesity and weight gain among middle-aged women. Int J Obes Relat Metab Disord.2004; 28:1569-74.

27. Dwyer LA, Bolger N, Laurenceau JP, Patrick H, Oh AY, Nebeling LC, et al. Autonomous motivation and fruit/vegetable intake in parentadolescent dyads. Am J Prev Med. 2017; 52:863-71.

28. Vereecken C, Pedersen TP, Ojala K, Krølner R, Dzielska A, Ahluwalia $\mathrm{N}$, et al. Fruit and vegetable consumption trends among adolescents from 2002 to 2010 in 33 countries. Eur J Public Health. 2015; 25:169.

29. Morita N, Nakajima T, Okita K, Ishihara T, Sagawa M, Yamatsu K. Relationships among fitness, obesity, screen time and academic achievement in Japanese adolescents. Physiol Behav. 2016; 163:161-6.

30. Torrijos-Niño C, Martínez-Vizcaíno V, Pardo-Guijarro MJ, García-Prieto JC, Arias-Palencia NM, Sánchez-López M. Physical fitness, obesity, and academic achievement in schoolchildren. J Pediatr. 2014 165:104-9.

31. LaGrotte C, Fernandez-Mendoza J, Calhoun SL, Liao D, Bixler EO, Vgontzas AN. The relative association of obstructive sleep apnea, obesity and excessive daytime sleepiness with incident depression: a longitudinal, population-based study. Int J Obes (Lond). 2016; 40:1397-404.

32. Nisar N, Qadri MH, Fatima K, Perveen S. Dietary habits and life style among the students of a private medical university Karachi. J Pak Med Assoc. 2009; 59:98-101.

33. Yahya F, Zafar R, Shafiq S. Trend of fast food consumption and its effect on Pakistani society. Food Sci Qual Manag. 2013; 11:1-8.

34. Jike $\mathrm{M}$, Itani $\mathrm{O}$, Watanabe N, Buysse DJ, Kaneita Y. Long sleep duration and health outcomes: A systematic review, meta-analysis and metaregression. Sleep Med Rev. 2018; 39:25-36.

35. Moreno-Vecino B, Arija-Blázquez A, Pedrero-Chamizo R, Gómez-Cabello A, Alegre LM, Pérez-López FR, et al. Sleep disturbance, obesity, physical fitness and quality of life in older women: EXERNET study group. Climacteric. 2017; 20:72-9.

36. Aziz S, Ain WN, Majeed R, Khan MA, Qayum I, Ahmed I, et al. Growth centile charts (anthropometric measurement) of Pakistani pediatric population. J Pak Med Assoc. 2012; 62:367-77. 